\title{
Gender Differences in the Link Between Marital Quality and Cognitive Decline Among Older Adults in Korea
}

\author{
Yujin Kim $\bowtie$ \\ Department of Sociology, Kangwon National University, Chuncheon, Republic of Korea
}

\begin{abstract}
Objective This study aimed to investigate the association between positive marital quality and cognitive health over time and to examine gender differences in this association.

Methods Drawing on 2006-2018 Korean Longitudinal Study of Aging data ( $\mathrm{n}=7,427$ respondents, 35,066 person-year observations), a series of hybrid mixed-effects models were used to estimate the effects of time-invariant (gender) and time-variant (marital quality) variables on within-person changes and on between-person differences in cognitive decline over the observation period.

Results The results showed that individuals' likelihood of having higher cognitive health grew when their spousal relationship became more positive and that, compared with those with lower levels of marital quality, people with higher levels of marital quality were more likely to have higher cognitive health. Interestingly, improvements in marital quality were more beneficial for men than for women, whereas level of marital quality had similar effects on men's and women's cognitive health.
\end{abstract}

Conclusion Couple-based intervention programs aiming to improve marital quality should be encouraged, especially among older adults.

Psychiatry Investig 2021;18(11):1091-1099

Keywords Marital quality; Cognitive decline; Gender; Longitudinal study; South Korea.

\section{INTRODUCTION}

As population aging has increased in South Korea (hereafter Korea), cognitive impairment and dementia have become major challenges for public health and social care. Researchers and scholars have identified multiple risk factors for cognitive impairment and dementia over the life course. ${ }^{1,2}$ One category of factors that has recently received a great deal of attention is the link between social relationships and cognitive decline in later life. Social relationships are multidimensional, with aspects ranging from the structure of relationships (i.e., social networks) to relationship quality. ${ }^{3}$ Interestingly, relationship quality has been found to be linked more strongly to cognition than to social network size. ${ }^{3,4}$

The quality of social relationships, particularly marital qual-

Received: April 11, 2021 Revised: July 22, 2021

Accepted: August 29, 2021

$\triangle$ Correspondence: Yujin Kim, PhD

Department of Sociology, Kangwon National University, 1 Kangwondaehak-gil, Chuncheon 24341, Republic of Korea

Tel: +82-33-250-6863, Fax: +82-33-259-5611, E-mail: yjkim3@kangwon.ac.kr

(c) This is an Open Access article distributed under the terms of the Creative Commons Attribution Non-Commercial License (https://creativecommons.org/licenses/by$\mathrm{nc} / 4.0$ ) which permits unrestricted non-commercial use, distribution, and reproduction in any medium, provided the original work is properly cited. ity (i.e., whether one's marriage is better or worse), is especially important in shaping cognitive health among older adults. ${ }^{5}$ In general, marital quality is conceptualized as an overall evaluation of one's marriage. Positive marital quality indicates high levels of marital satisfaction and positive attitudes toward one's spouse-characteristics that are interrelated rather than distinct. ${ }^{6}$ In addition, the life course perspective posits that marital quality is not static but instead tends to decline over time; although it may improve with age because of personal experience and maturation, the level of marital quality declines as marital duration increases, perhaps as a result of diminished compatibility or boredom. ${ }^{7}$ For many older adults whose children have left home, their spouse is their primary social tie and confidant, as they share the same space and spend time together on a daily basis. This situation suggests that the level of marital quality-especially spousal satisfaction-holds great significance for older adults' cognitive health. ${ }^{8}$

Positive marital quality may be associated with better cognitive performance among older adults through the provision of instrumental and emotional support, the promotion of healthy lifestyle behaviors, and the encouragement of coping resources, all of which reduce perceived stress. ${ }^{3,9,10}$ Previous studies conducted mostly in Western countries have found in- 
consistent results regarding the association between marital quality and cognitive decline: Some have found higher levels of marital quality to be linked to less cognitive decline, ${ }^{4,5}$ whereas others have found no significant association. ${ }^{3,11}$

In addition to examining marital quality and cognitive health, previous studies have also paid special attention to gender differences in the association between marital quality and cognitive decline. ${ }^{8,12}$ Because of the importance of gender throughout the life course, it likely shapes the experience of marriage differently for men and women. ${ }^{13}$ Although the general rate of decline in marital quality over time is similar for men and women, men tend to report relatively high levels of marital quality because they enjoy greater marital benefits, compared with women. ${ }^{7}$ Men also receive more health benefits, such as emotional support and health behavior regulation, from their spouses. ${ }^{14}$ As individuals age, they are faced with the shrinkage of their social networks and the loss of key figures in their lives. ${ }^{15}$ Older men tend to seek their closest relationships among family members, whereas older women have confidants both inside and outside their families. ${ }^{16}$ However, previous studies conducted mostly in Western countries have found no gender difference in the effect of the presence of a spouse $\mathrm{e}^{17-19}$ or having a positive spousal relationship ${ }^{8}$ on cognitive impairment. This may imply that, although men are more likely to enjoy higher levels of marital quality compared with women, specific levels of marital quality have similar effects on men's and women's cognitive health.

Korea is an interesting case for examining the association between marital quality and cognitive decline and for investigating gender differences in this association. In addition to being among the world's most rapidly aging countries, Korea has also experienced large changes in family formation behaviors (i.e., an increase in divorce and a retreat from marriage) over the last several decades. The divorce rate among Koreans aged 50 years or older has continuously increased since 2008, reaching a similar level to the divorce rate found among 30 year-olds in $2018 .^{20}$ Despite the rapid changes in family formation behaviors and the improvement in the social status of women in Korea, gender inequality and social norms regarding women's traditional obligations within marriage persist, resulting in, for example, a strict division of domestic labor and strong childcare expectations..$^{21}$ Among Organization for Economic Co-operation and Development countries, Korea ranks lowest both on the glass-ceiling index ${ }^{22}$ and in men's share of housework in dual-income couples, which was only $16.5 \%$ in $2014 .{ }^{23}$ This unequal situation may reduce women's marital quality and increase marital strain/conflict. Compared with men, women are known to be more sensitive or vulnerable to marital strain/conflict. ${ }^{3,8,11}$ In contrast to the previous work in Western countries, a study in Korea found that the presence of a spouse provided greater cognitive health benefits to men than to women, ${ }^{24}$ so it is likely that positive marital quality and improvements in marital quality have greater beneficial effects on cognitive health for men than for women.

Using data from a nationally representative sample collected over a 12-year period, this study aimed to investigate 1) whether marital quality changes over time, 2) whether marital quality is negatively associated with cognitive decline over time, and 3) whether this association differs by gender among older adults in Korea. To achieve these aims, the study used 1) growth curve models to examine individuals' changes in marital quality and 2) hybrid mixed-effects models to estimate the effects of both time-invariant (e.g., gender) and timevariant (e.g., marital quality) variables on within-person changes and between-person differences in cognitive decline over the observation period.

\section{METHODS}

\section{Study sample}

The study used data from the Korean Longitudinal Study of Aging (KLoSA), a nationally representative longitudinal survey of non-institutionalized Koreans aged 45 years or older. The KLoSA has been conducted every two years since 2006 $(n=10,254)$. I used data from the seven waves of the KLoSA conducted from 2006 to 2018, including the most recent wave available. The KLoSA collects information on health, health insurance, health behaviors, the impact of social welfare policies, and socioeconomic status. ${ }^{25}$

To take the possibility of reverse causality between marital quality and cognitive impairment into account, the analytic sample was restricted to those who were married (2,283 respondents excluded) and who had not experienced cognitive impairment (544 respondents excluded) at the baseline survey in 2006, leaving 7,427 respondents for analysis. The data were then converted into person-years, with observations beginning at the first wave and ending at exit from marriage via divorce/separation or spouse's death, the most recent survey interview, or a survey with missing information on cognitive function because of the respondent's death or nonresponse (35,066 person-year observations).

Marital quality may be inversely associated with mortality risk, which would mean that people in marriages that survived over the 12-year study period were a relatively healthy subpopulation of older adults. In addition, marital quality may be associated with type of marital dissolution; people exiting marriage via divorce likely have poorer marital quality compared with those who are widowed. To consider the problems of mortality selection and nonrandom attrition, I constructed an indicator of attrition type (remaining in the survey $=0$, divorce/ 
separation $=1$, spouse's death $=2$, respondent's death $=3$, and nonresponse $=4$ ), which I included in the analyses as four binary variables indicating the different attrition types (treating "remaining in the survey" as the reference category). This study was approved by the Institutional Review Board of Kangwon National University (IRB approval number: KWNUIRB2021-04-008).

\section{Measures}

\section{Dependent variable}

Cognitive performance was assessed using the Korean version of the Mini-Mental State Examination (MMSE). The MMSE has been widely used to evaluate global cognitive health status. $^{26-28}$ Total MMSE scores range from 0 to 30, with higher scores indicating higher levels of cognition.

\section{Independent variables}

In each survey wave, positive marital quality was measured by asking "How satisfied are you with your spouse?" Responses ranged from 0 to 100 , with higher scores indicating more positive marital quality. A single measure of marital quality was used in this study because this was the only relevant measure available in the KLoSA. However, previous studies have found that effect size does not vary significantly across various measures of marital quality, with authors noting that using a "gold-standard" marital quality measure may not be critical because most measures are sufficient to capture general marital quality. ${ }^{6,29}$

Several factors associated with positive marital quality and cognitive health-socioeconomic resources, health, and social engagement-were included in the analysis as covariates. First, education, employment status, and household income were included as indicators of socioeconomic status. Education was measured using three dummy variables (middle school or less $=0$, high school=1, and college or higher=2), and employment status was coded to compare those who were currently employed $(=1)$ with others $(=0)$ in each survey wave. Total household income was divided into quartiles in each survey wave. Second, for health status, vascular risk factors were considered using self-reported diagnoses of obesity (yes= 1, no $=0$ ), heart disease (yes $=1$, no $=0$ ), cerebrovascular disease (yes $=1$, no $=0$ ), diabetes (yes $=1$, no $=0$ ), and hypertension (yes $=$ 1, no $=0$ ) in each survey wave. I also included hearing loss, which was treated as a time-varying variable that identified whether a respondent had difficulties in daily life because of poor hearing (yes $=1$, no $=0$ ). Third, to assess the structure of social relations, social engagement was included as a timevarying assessment of participation in socially productive activities through church or other religious gatherings, friend- ship organizations, leisure/sports activities, alumni associations, volunteering, or political gatherings. This variable was categorized into three groups: never or almost never participated in any activities $(=0)$, participated once or twice a month $(=1)$, and participated almost every week or more $(=2)$. Finally, residential area (metropolitan area $=0$, city $=1$, rural area $=2$ ), gen$\operatorname{der}(\operatorname{men}=0$, women $=1)$, and age (mean-centered) were included as sociodemographic variables.

\section{Analytic plan}

To determine whether the effects of positive marital quality on cognitive health over time differed by gender, this study used a two-step process. In the first step, including the variables of age, gender, and marital quality, I used growth curve models to test whether marital quality changed over time and whether the changes in marital quality differed by gender. In the second step, I used hybrid mixed-effects models (hereafter hybrid models) to estimate "within" effects in random effects models by decomposing level-1 (i.e., wave) variables into "between" and "within" components. ${ }^{30}$ Using hybrid models allowed me to estimate the effects of time-invariant (i.e., gender and education) and time-variant (i.e., marital quality, age, employment, health, and social engagement) variables for both within-person changes and between-person differences. A series of hybrid models were estimated. Model 1 estimated the effects of age, gender, attrition type, and marital quality on cognitive decline. Model 2 examined whether and to what extent the effect of positive marital quality on cognitive health was explained by socioeconomic conditions (i.e., employment, education, household income, and residential area). Model 3 added health variables, and Model 4 further included social engagement. The final model, Model 5, added interaction terms for gender and marital quality to Model 4 to allow the effects of marital quality on cognitive health to differ for men and women.

\section{RESULTS}

\section{Descriptive results}

Table 1 presents the weighted descriptive statistics (percentages and means) for all the examined variables at baseline (2006) in the total sample and separately by gender. The average MMSE score was 27.42, indicating normal cognitive status, and the average overall rating of marital quality (i.e., the rating of the spousal relationship out of 100) was 72 . The mean respondent age was 56 years, and women made up about half of the sample. Women were less likely than men to have a high MMSE score, to positively evaluate their spousal relationship, to be highly educated, and to be employed. As expected, women were more likely than men to participate in social activities. 
Table 1. Weighted descriptive statistics of the analytic sample in 2006 by gender $(N=7,427)$

\begin{tabular}{|c|c|c|c|c|}
\hline \multirow{2}{*}{ Variable } & \multirow{2}{*}{ Total (mean, \%) } & \multicolumn{3}{|c|}{ Gender } \\
\hline & & Men & Women & t-test \\
\hline MMSE score & 27.42 & 27.70 & 27.08 & $* * *$ \\
\hline Marital quality & 72.14 & 74.51 & 69.40 & $* * *$ \\
\hline Gender (women) & 46.40 & & & \\
\hline Age & 56.30 & 56.28 & 55.72 & $* *$ \\
\hline \multicolumn{5}{|l|}{ Socioeconomic status } \\
\hline \multicolumn{5}{|l|}{ Education } \\
\hline Middle school or less & 48.02 & 39.03 & 58.41 & $* * *$ \\
\hline High school & 36.86 & 39.40 & 33.92 & $* * *$ \\
\hline College or higher & 15.13 & 21.57 & 7.68 & $* * *$ \\
\hline Currently working & 52.55 & 70.51 & 31.80 & $* * *$ \\
\hline \multicolumn{5}{|l|}{ Household income quartiles } \\
\hline Q1 & 23.83 & 23.42 & 24.29 & \\
\hline Q2 & 21.69 & 20.56 & 22.99 & $* *$ \\
\hline Q3 & 31.10 & 31.80 & 30.29 & \\
\hline Q4 & 23.39 & 24.21 & 22.43 & $*$ \\
\hline \multicolumn{5}{|l|}{ Region } \\
\hline Metropolitan area & 46.33 & 45.83 & 46.91 & \\
\hline City & 33.81 & 34.22 & 33.33 & \\
\hline Rural & 19.86 & 19.95 & 19.76 & \\
\hline \multicolumn{5}{|l|}{ Health variables } \\
\hline Hypertension & 21.28 & 21.30 & 21.25 & \\
\hline Cerebrovascular disease & 1.90 & 2.35 & 1.39 & $* *$ \\
\hline Heart disease & 3.46 & 3.58 & 3.32 & \\
\hline Diabetes & 9.49 & 10.96 & 7.79 & $* * *$ \\
\hline Obesity & 23.82 & 23.65 & 24.02 & \\
\hline Hearing loss & 2.90 & 3.27 & 2.48 & \\
\hline \multicolumn{5}{|l|}{ Participation in social activities } \\
\hline Never or almost never & 31.12 & 32.82 & 29.16 & $* * *$ \\
\hline Once or twice a month & 38.78 & 41.39 & 35.75 & $* * *$ \\
\hline Almost every week & 30.1 & 25.79 & 35.08 & $* * *$ \\
\hline \multicolumn{5}{|l|}{ Attrition type } \\
\hline Stayed in the survey & 73.88 & 76.67 & 70.66 & $* * *$ \\
\hline Divorce/separation & 0.96 & 1.22 & 0.66 & $*$ \\
\hline Spouse's death & 6.60 & 2.40 & 11.45 & $* * *$ \\
\hline Respondent's death & 0.81 & 1.25 & 0.30 & $* * *$ \\
\hline No answer/no interview & 17.75 & 18.46 & 16.93 & \\
\hline
\end{tabular}

${ }^{*} \mathrm{p}<0.05 ;{ }^{* *} \mathrm{p}<0.01 ;{ }^{* *} \mathrm{p}<0.001$. MMSE, Mini-Mental State Examination

\section{Growth curve model results}

To describe marital relationship changes over time, Figure 1 presents the predicted age trajectories in marital relationships for the total sample and separately for men and women. The values were estimated using growth curve models includ- ing the variables of age, gender, and marital quality. Marital quality tended to decline as individuals aged, which may also reflect marital duration, possibly indicating diminished compatibility or boredom with increasing time spent in the relationship. Declines in marital quality were observed for both 


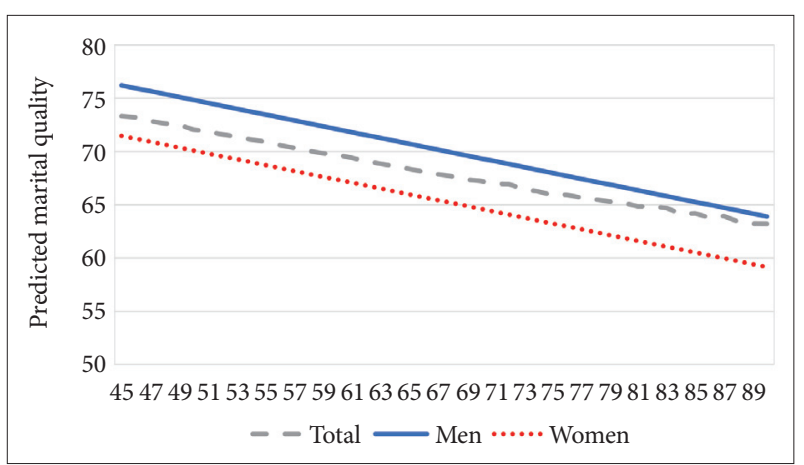

Figure 1. Predicted age trajectories of marital quality by gender.

men and women, although, across all ages, compared with women, men consistently reported higher levels of marital quality.

\section{Hybrid model results}

In Table 2, which presents the results of the hybrid models, Model 1 shows the associations of age, gender, marital quality, and attrition type with cognitive health. For the time-invariant (random) effects, as expected, women were less likely than men to have higher levels of cognition. The within and between effects of age indicated that individuals were increasingly likely to have lower levels of cognition as they aged and that older people were also more likely than younger people to have lower levels of cognition. In addition, the within and between effects of marital quality showed that individuals were increasingly likely to have higher levels of cognition when their spousal relationship became more positive and also that people with higher levels of marital quality were more likely than those with lower levels of marital quality to have higher levels of cognition.

In Model 2, the effects of marital quality became smaller but remained significant after socioeconomic status (i.e., education, household income, employment, and residential area) was taken into account. People with a middle school education or less were less likely to have higher levels of cognition compared with those with a high school education or higher. As for employment status, the within effects indicated that a change from unemployment to employment was associated with increased cognition, and the between effects showed that individuals with a job were more likely to have better cognition outcomes compared with those without a job.

In Model 3, which added health variables to Model 2, the between and within effects of marital quality remained significant. The within and between effects of health revealed significant associations with cognition: Individuals' cognition decreased after a diagnosis of hypertension, cerebrovascular disease, or heart disease. People with cerebrovascular disease or diabetes were less likely to have better cognition than were those without these diseases. Model 4 added social engagement, and, even after taking the structural components of social network into account, the effects of marital quality remained significant. As expected, the within and between effects of social engagement indicated significant associations with cognitive health. When individuals participated more actively in any type of social activity, their cognitive performance improved. In addition, people who participated in social activities more frequently were more likely to have better cognition.

The final model, Model 5, examined gender differences in the effects of positive marital quality by including interaction terms for gender and marital quality. Interestingly, the within effects of these interaction terms showed significant associations with cognitive health, whereas the between effects of the interaction terms did not. Specifically, the health benefits of improving marital quality were relatively large for men; positive changes in marital quality within individuals were associated with improved cognitive performance, and these benefits were larger for men than for women. In contrast to the within effects, the between effects of marital quality did not differ significantly by gender, suggesting that the effects of the level of marital quality on cognitive health were similar for men and women.

\section{DISCUSSION}

Because of the importance of marital quality among older adults in Korea, this study investigated whether and to what extent positive marital quality is related to cognitive decline over time, as well as the moderating effect of gender on this association. First, in line with a previous study, ${ }^{7}$ found that marital quality declines over time, which is likely an effect of marital duration, and that men are more likely than women to report higher levels of marital quality, probably because of the relatively large benefits of marriage for men. Second, unlike previous studies in Western countries, ${ }^{8,11}$ this study found that both having a positive spousal relationship and improving this relationship are related to better cognitive health. Despite changes in the structure and function of the family in Korea over the last few decades, family-oriented culture, including the normative expectation of marriage and traditional values and attitudes associated with marital relationships, remains relatively strong in this context, particularly for older generations. ${ }^{31}$ The salience of marriage and marital quality in Korea may augment the health benefits of positive marital quality, likely through the high levels of social and emotional support provided by the spouse. Both the actual receipt of emotional support and one's beliefs regarding the availability of such support may protect against mental and physical health problems, including depression, heart disease, and hyperten- 


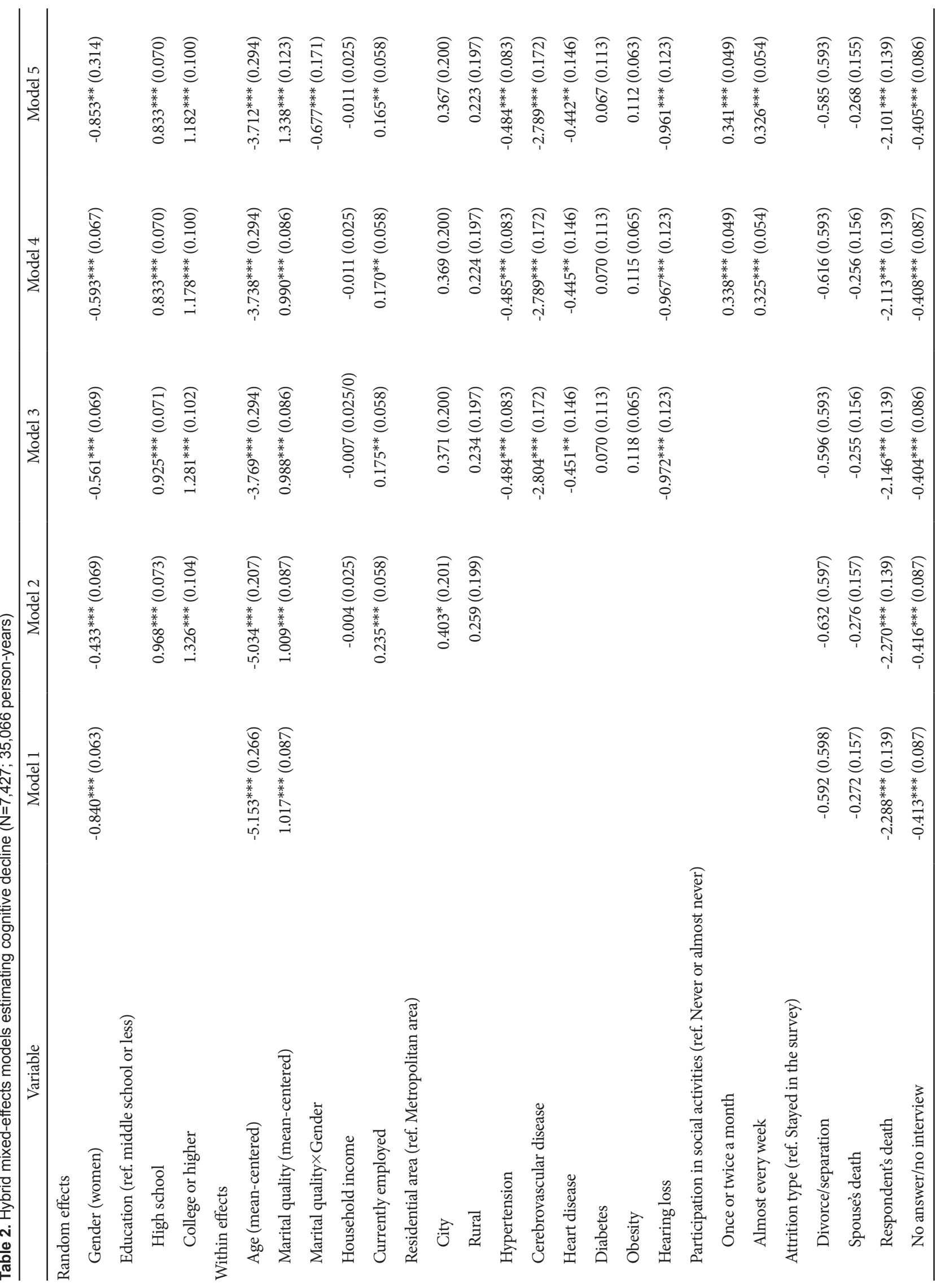




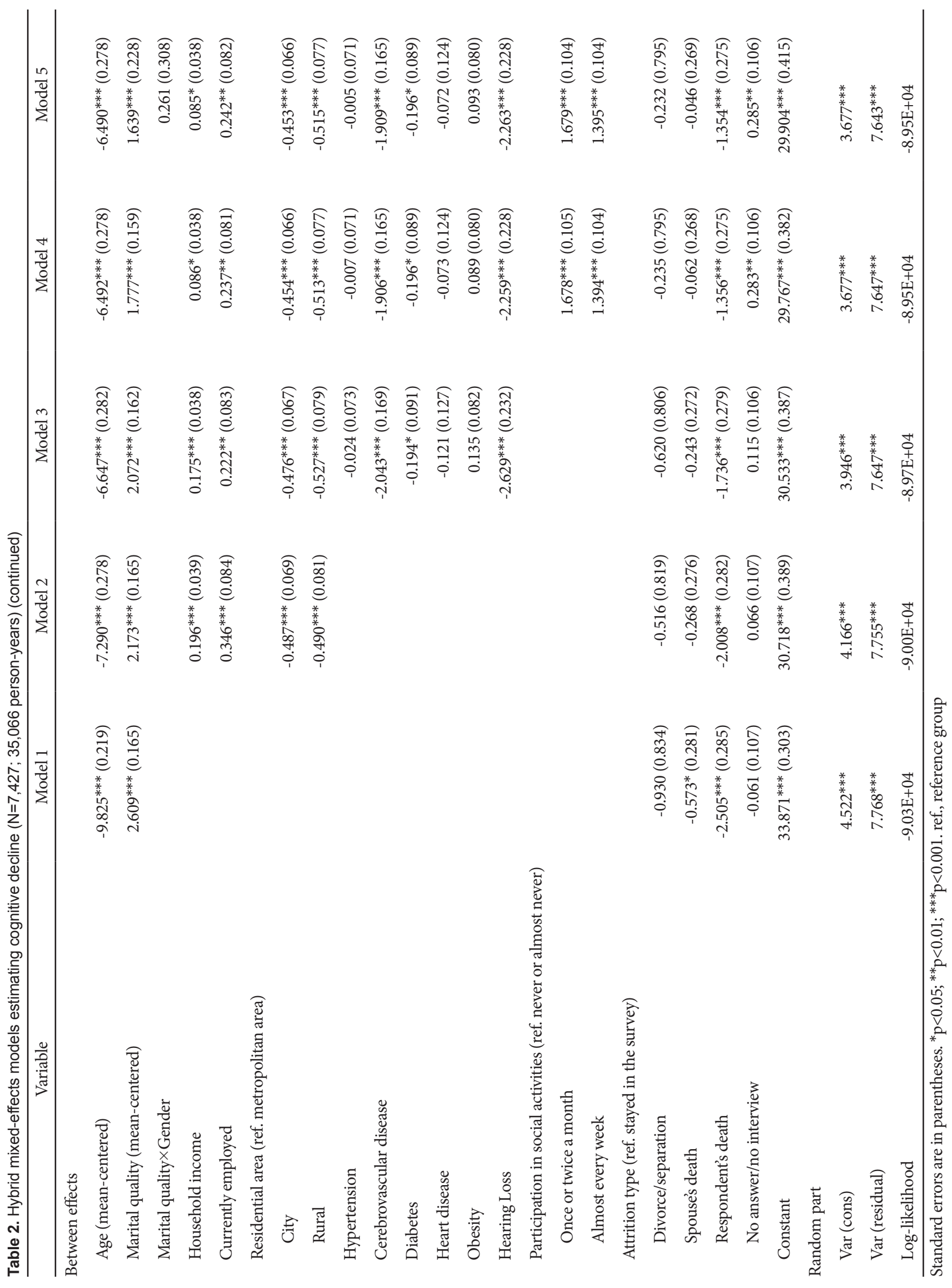


sion, which are associated with cognitive decline. ${ }^{8,12,32}$ Positive marital quality may also promote health-enhancing behaviors (i.e., exercise and a healthy diet), discourage health-compromising behaviors (i.e., smoking and binge drinking), and encourage health care utilization. ${ }^{12,33}$ Further, positive and supportive interactions between marital partners may protect against cognitive decline by reducing individuals' psychological responses to stress outside the home ${ }^{12,34}$ and facilitating more active cognitive engagement. ${ }^{32}$

Another important finding of this study is that within-individual improvements in marital quality are more beneficial for cognitive health among men than among women. However, the effect of a particular level of marital quality on cognitive health does not differ by gender. This finding of no significant gender differences in the between effects of marital quality is somewhat consistent with a previous study ${ }^{8}$ that focused mostly on between-person differences and did not consider time-varying aspects of marital quality within individuals. In societies such as Korea that have relatively high levels of gender inequality, a patriarchal culture, and a traditional gender role ideology, ${ }^{31}$ it is likely to be women who provide social and emotional support to their spouses when needed, regulating their spouses' health behaviors, performing the majority of childcare tasks and other household chores, and helping their spouses to build and maintain social relationships with others, whereas men are likely to be more responsible for providing economic resources. ${ }^{14,35}$ Relatedly, it is possible that the effects of improving marital quality on cognitive health may be more visible and immediate for men than for women. In addition, this study revealed that, in Korea, across age groups, men tend to report higher levels of marital quality compared with women; thus, it is likely that a higher proportion of men than women enjoy cognitive health benefits from positive marital quality, although these benefits do not differ for men and women with the same level of marital quality.

The results of the present study should be interpreted in light of several limitations. First, the KLoSA included only a single measure of positive marital quality. Improvement in the measurement of marital quality would allow for a better examination of the effects of diverse aspects of marital qualityincluding both positive and negative dimensions-on cognitive health. Marital strain/conflict is a known risk factor for cognitive health, and, compared with men, women are more vulnerable to marital conflict. ${ }^{3,8,11}$ Future research should consider both positive and negative dimensions of marital quality and examine whether and to what extent the effects of positive and negative marital quality on cognitive health differ for older men and women in Korea. Second, because of data limitations, this study could not include marital duration, which is likely to be related to changes in marital quality. Third, this study was unable to distinguish between age and cohort effects in the association of marital quality with cognitive health. The age differences in marital quality are probably at least partially explained by cohort differences. Birth (and marriage) cohorts are influenced by the historical and cultural contexts of their experiences, which probably affect their marital relationship evaluations. However, this study could not distinguish between age and cohort effects because the KLoSA currently covers a 12-year observation period, which is too short to include individuals of the same age range from different birth cohorts. Finally, marriages of poor quality and individuals in poor health may have been removed from the study population over time, leaving a relatively healthy sample with higher-quality marriages at older ages. To take these selection effects into account, this study included a variable for attrition type, but the possibility of selection bias remains.

Despite these limitations, by examining the effects of both within-person changes and between-person differences in marital quality on cognitive health over time, this study showed that both high levels of marital quality and improvements in marital quality had positive effects on the cognitive health of older adults in Korea. As individuals' levels of daily social and formal interactions decline with age, the quality of core relationships may play an increasingly important role in alleviating cognitive decline. Couple-based intervention programs aiming to improve marital quality by enhancing effective communication and reducing negative/harmful behaviors should be encouraged, especially among older people, whose risk of experiencing cognitive impairment is relatively high.

\section{Availability of Data and Material}

The datasets generated or analyzed during the study are available from the corresponding author on reasonable request.

\section{Conflicts of Interest}

The author has no potential conflicts of interest to disclose.

\section{ORCID iD}

Yujin Kim https://orcid.org/0000-0002-4042-5615

\section{Funding Statement \\ None}

\section{REFERENCES}

1. Livingston G, Sommerlad A, Orgeta V, Costafreda SG, Huntley J, Ames D, et al. Dementia prevention, intervention, and care. Lancet 2017;390: 2673-2734.

2. Kim Y. Risk and Protective Factors for the onset of cognitive impairment in Korea: a 10-year longitudinal panel study. Psychiatry Investig 2020;17:769-776.

3. Zahodne LB, Ajrouch KJ, Sharifian N, Antonucci TC. Social relations and age-related change in memory. Psychol Aging 2019;34:751-765.

4. Béland F, Zunzunegui MV, Alvarado B, Otero A, Del Ser T. Trajectories of cognitive decline and social relations. J Gerontol B Psychol Sci Soc Sci 2005;60:320-330. 
5. Frith E, Loprinzi PD. Social support and cognitive function in older adults. Best Pract Ment Health 2017;13:41-49.

6. Robles TF, Slatcher RB, Trombello JM, McGinn MM. Marital quality and health: a meta-analytic review. Psychol Bull 2014;140:140-187.

7. Umberson D, Williams K, Powers DA, Chen MD, Campbell AM. As good as it gets? A life course perspective on marital quality. Soc Forces 2005;84:493-511.

8. Xu M, Thomas PA, Umberson D. Marital quality and cognitive limitations in late life. J Gerontol B Psychol Sci Soc Sci 2016;71:165-176.

9. Lee Y, Back JH, Kim J, Kim SH, Na DL, Cheong HK, et al. Systematic review of health behavioral risks and cognitive health in older adults. Int Psychogeriatr 2010;22:174-187.

10. Wilson RS, Schneider JA, Boyle PA, Arnold SE, Tang Y, Bennett DA. Chronic distress and incidence of mild cognitive impairment. Neurology 2007;68:2085-2092.

11. Windsor TD, Gerstorf D, Pearson E, Ryan LH, Anstey KJ. Positive and negative social exchanges and cognitive aging in young-old adults: Differential associations across family, friend, and spouse domains. Psychol Aging 2014;29:28-43.

12. Pillemer SC, Holtzer R. The differential relationships of dimensions of perceived social support with cognitive function among older adults. Aging Ment Health 2016;20:727-735.

13. Martin PY. Gender as social institution. Soc Forces 2004;82:1249-1273.

14. Liu H, Umberson DJ. The times they are a changin': Marital status and health differentials from 1972 to 2003. J Health Soc Behav 2008;49: 239-253.

15. Antonucci T. Social Supports and Social Relationships. In: Binstock RH, George LK, Editors. Handbook of Aging and the Social Sciences, 3rd Ed. San Diego, CA: Academic Press; 1990, p. 205-226.

16. Belle D. Gender Differences in the Social Moderators of Stress. In: Monat A, Lazarus RS, Editors. Stress and Coping: An Anthology. New York, NY: Columbia University Press,1991, p.258-226.

17. Håkansson K, Rovio S, Helkala EL, Vilska AR, Winblad B, Soininen H, et al. Association between mid-life marital status and cognitive function in later life: population based cohort study. BMJ 2009;339:b2462.

18. Liu H, Zhang Y, Burgard SA, Needham BL. Marital status and cognitive impairment in the United States: evidence from the National Health and Aging Trends Study. Ann Epidemiol 2019;38:28-34.

19. Sundström A, Westerlund O, Kotyrlo E. Marital status and risk of dementia: a nationwide population-based prospective study from Sweden. BMJ open 2016;6:e08565.

20. Statistics Korea. 2018 marriage and divorce statistics. Statistics Korea; 2019. Available at http://webcache.googleusercontent.com/ search?q=cache:LwDFRHy6rToJ:m.kostat.go.kr/board/file_dn.jsp\%3F aSeq\%3D373728\%26ord\%3D4+\&cd=3\&hl=ko\&ct=clnk\&gl=kr. Ac- cessed Jan 3, 2021.

21. Tsuya NO, Mason KO. Changing Gender Roles and Below-Replacement Fertility in Japan. In: Mason KO, Jensen A, Editors. Gender and Family Change in Industrialized Countries. Oxford: Clarendon Press; 1995, p.139-167.

22. More cracks appear. Available at: https://www.economist.com/business/2021/03/06/is-the-lot-of-female-executives-improving. Accessed July $1,2021$.

23. Results of analysis of employment trend of duel-income parents. Available at: http://www.moel.go.kr/news/enews/report/enewsView.do;jsessionid=Cg9xVfp4i94h76yQ7ZL1BhQUvaMVsl15Gm1YTvz5SPfQGi q8JIQRejtQBBmC8Aab.moel_was_outside_servlet_wwwl?news_ seq $=7812$. Accessed July 3, 2021.

24. Kim Y. Gender Differences in the link between marital status and the risk of cognitive impairment: results From the Korean Longitudinal Study of Aging. Int J Aging Hum Dev 2021 [Online ahead of print].

25. KLoSA. 2018 KLoSA User's Guide. Chungcheongbuk-do: Korea Employment Information Service; 2018.

26. Folstein MF, Folstein SE, McHugh PR. "Mini-mental state": a practical method for grading the cognitive state of patients for the clinician. J Psychiatr Res 1975;12:189-198.

27. Tombaugh TN, McIntyre NJ. The Mini-Mental State Examination: a comprehensive review. J Am Geriatr Soc 1992;40:922-935.

28. Mitchell AJ. A meta-analysis of the accuracy of the Mini-Mental State Examination in the detection of dementia and mild cognitive impairment. J Psychiatr Res 2009;43:411-431.

29. Fincham FD, Bradbury TN. The assessment of marital quality: a reevaluation. J Marriage Fam 1987;49:797-809.

30. Schunck R, Perales F. Within-and between-cluster effects in generalized linear mixed models: a discussion of approaches and the xthybrid command. Stata J 2017;17:89-115.

31. Raymo JM, Park H, Xie Y, Yeung WJ. Marriage and family in East Asia: Continuity and change. Annu Rev Soc 2015;41:471-492.

32. Seeman TE, Lusignolo TM, Albert M, Berkman L. Social relationships, social support, and patterns of cognitive aging in healthy, high-functioning older adults: MacArthur studies of successful aging. Health Psychol 2001;20:243-255.

33. Lachman ME, Neupert SD, Agrigoroaei S. The Relevance of Control Beliefs for Health and Aging. In: Schaie KW, Willis SL, Editors. Handbook of the Psychology of Aging. London: Elsevier, 2011, p.175-190.

34. Cohen S. Social relationships and health. Am Psychol 2004;59:676-684.

35. Lee GR, DeMaris A, Bavin S, Sullivan R. Gender differences in the depressive effect of widowhood in later life. J Gerontol B Psychol Sci Soc Sci 2001;56:56-61. 